\title{
Optimization of conditions for treatment of ZnSe crystal surfaces by chemical etching
}

\author{
V.M. Tomashyk ${ }^{1}$, A.S. Kravtsova ${ }^{1}$, Z.F. Tomashyk ${ }^{1}$, I.B. Stratiychuk ${ }^{1}$, S.M. Galkin ${ }^{2}$ \\ ${ }^{I} V$. Lashkaryov Institute of Semiconductor Physics, National Academy of Sciences of Ukraine, \\ 41, prospect Nauky,03028Kyiv; e-mail: graceful_anna@mail.ru \\ ${ }^{2}$ Institute for Scintillation Materials, National Academy of Sciences of Ukraine, \\ 60, Lenin Ave, Kharkiv
}

\begin{abstract}
The process of chemical polishing the undoped and doped ZnSe crystals surface with $\mathrm{H}_{2} \mathrm{O}_{2}-\mathrm{HBr}$ etchants has been studied. The dependence of the samples polishing rate on the concentration of $\mathrm{H}_{2} \mathrm{O}_{2}$ in $\mathrm{HBr}$ solution has been investigated. Surface states after chemical etching have been established using electron and atomic force microscopies, and it was shown that the surface state is improved after chemical etching. Etchant selection to develop slow polishing compositions for chemicalmechanical polishing the investigated materials has been made. Concentration regions of polishing solutions have been found for various types of $\mathrm{ZnSe}$ surface treatment: to remove the damaged layer, to control the etching rate, to obtain samples of a given thickness.
\end{abstract}

Keywords: semiconductor, zinc selenide, etchant, crystal, chemical-mechanical polishing, chemical-dynamic polishing.

Manuscript received 16.01.13; revised version received 22.02.13; accepted for publication 19.03.13; published online 25.06.13.

\section{Introduction}

The traditional technology of modern electronics for manufacturing elements of devices with semiconductor II-VI compounds involves the use of abrasive or chemical treatment methods at all stages of their production [1]. In this regard, great importance is the development of defect-free single crystals manufactured technology, which includes transaction oriented cutting plates from monocrystalline ingots, the application workpieces manufacturing of given configuration and obtaining the required wafer surface geometry using chemical mechanical (CMP) and chemical dynamic polishing (CDP) technologies that prevent formation and transformation of defects [2].

Chemical modification of the II-VI semiconductor compounds surfaces is often carried out using bromine containing mixtures [3-8]. To obtain more perfect polished surface of $\mathrm{ZnSe}$ crystals, bromine containing etching compositions such as $\mathrm{Br}_{2}$ in methanol or ethanol with different bromine content has been used [9-15] (Table 1). For chemical etching the $\mathrm{ZnSe}$ crystals with orientation (111) a solution of 0.4 vol.\% $\mathrm{Br}_{2} / \mathrm{CH}_{3} \mathrm{OH}$ at the boiling point can be used [10]. In $[11,12]$, zinc selenide semiconductor wafers were treated with 2 vol.\% solution of $\mathrm{Br}_{2}$ in $\mathrm{CH}_{3} \mathrm{OH}$ at $T=$ $273-283 \mathrm{~K}$. At the treating of $\mathrm{ZnSe}$ surfaces with 0.5 vol.\% solution of $\mathrm{Br}_{2}$ in $\mathrm{CH}_{3} \mathrm{OH}$, formation of etching pits on the polished plane (111) were observed [13]. In [14], after the previous mechanical treatment of $\mathrm{ZnSe}$ (111) crystals with the diamond paste of $0.25-\mu \mathrm{m}$ graininess, carried out was etching them with the 0.5 vol.\% solution of $\mathrm{Br}_{2}$ in $\mathrm{CH}_{3} \mathrm{OH}$. The processes of etching the doped $\mathrm{ZnSe}$ samples were carried out in the solution that contains 10 vol. $\% \mathrm{Br}_{2}$ in $\mathrm{C}_{2} \mathrm{H}_{5} \mathrm{OH}$ for $2 \min [15]$. 
Table 1. The etchant compositions for chemical treatment of $\mathrm{ZnSe}$ crystals.

\begin{tabular}{|c|c|c|c|}
\hline 1. & $\begin{array}{c}0.4 \% \mathrm{Br}_{2} \text { in } \\
\mathrm{CH}_{3} \mathrm{OH}\end{array}$ & $\begin{array}{c}\text { Using the hot solution } \\
\text { at its boiling point, } \\
\text { the orientation of } \\
\text { crystals (111) }\end{array}$ & {$[10]$} \\
\hline 2. & $\begin{array}{c}0.5 \% \mathrm{Br}_{2} \text { in } \\
\mathrm{CH}_{3} \mathrm{OH}\end{array}$ & $\begin{array}{c}\text { The etching pits are } \\
\text { located on a (111) plane }\end{array}$ & {$[13]$} \\
\hline 3. & $\begin{array}{c}0.5 \% \mathrm{Br}_{2} \text { in } \\
\mathrm{CH}_{3} \mathrm{OH}\end{array}$ & $\begin{array}{c}\text { The pretreatment was } \\
\text { performed by diamond } \\
\text { paste }(0.25 \mu \mathrm{m}), \\
\text { orientation of crystals } \\
(111)\end{array}$ & {$[14]$} \\
\hline 4. & $\begin{array}{c}2 \% \mathrm{Br}_{2}: 98 \% \\
\mathrm{CH}_{3} \mathrm{OH}\end{array}$ & $\begin{array}{c}T=273-283 \mathrm{~K} \\
{[9,}\end{array}$ & $11,12]$ \\
\hline 5. & $\begin{array}{c}10 \% \mathrm{Br} \text { in } \\
\mathrm{C}_{2} \mathrm{H}_{5} \mathrm{OH}\end{array}$ & $\begin{array}{c}\text { The process of etching } \\
\text { was carried out for } \\
2 \text { min }\end{array}$ & {$[15]$} \\
\hline
\end{tabular}

The high toxicity and difficulty of process conditions, when using the bromine containing etchants, require searching for a new, less toxic and more technological etching compositions with low dissolution rates of semiconductor surfaces. An alternative to bromine containing etchants is bromine emerging compositions, including solutions based on $\mathrm{H}_{2} \mathrm{O}_{2}-\mathrm{HBr}$, which can be used even at 291-298 K. In these mixtures, free bromine is produced in the process of interaction between components disappears. It means that all bromine takes part in the chemical etching.

In this paper, we report peculiarities of the chemical-mechanical etching of undoped and aluminum or tellurium doped $\mathrm{ZnSe}$ crystals in $\mathrm{H}_{2} \mathrm{O}_{2}-\mathrm{HBr}-$ ethylene glycol (EG) etching compositions and surface morphology after chemical etching, optimization of etchant compositions for semiconductors chemical polishing and technological conditions of CMP to use them in producing materials for making operation elements for optical and electronic devices, and selection of slow zinc selenide polishing compositions for CMP.

\section{Experimental}

The research was carried out using crystal wafers of undoped $\mathrm{ZnSe}$ (I) (without thermal annealing), $\mathrm{ZnSe}$ (II) (after thermal annealing) and doped $\mathrm{ZnSe}(\mathrm{Al})$ and $\mathrm{ZnSe}(\mathrm{Te})$ crystals grown by the Bridgman method.

The surface pretreatment of undoped and doped ZnSe before chemical polishing process included the following operations:

- $\quad$ cutting the relevant crystal ingots to wafers;

- mechanical treatment of surface (polishing with abrasives, mechanical polishing);

- $\quad$ removing the surface damaged layer by CMP;

- $\quad$ surface inter-cleaning after each stage of treatment.
For each of these steps we have developed the technological modes and recommendations to these operations.

Cutting the crystal ingots to wafers. According to our methods, the samples of undoped and doped $\mathrm{ZnSe}$ crystals were cut from grown single crystal ingots in a special unit by cutting wire with a diamond coating. The process was performed on stall at the following technological conditions (the string was moisten with distilled water in the cutting process): the diameter of the wire string $300 \mu \mathrm{m}$; speed of its motion $0.5 \mathrm{~m} / \mathrm{s}$; load on a crystal $15 \mathrm{~g}$; process duration 10 to $20 \mathrm{~min}$; cutting width $350 \mathrm{~mm}$, while the rate of crystal cutting was $200 \mathrm{~mm} / \mathrm{min}$.

The investigated samples were cut with a $1.2 \mathrm{~mm}$ thickness; the area of the substrate was not less than $25 \mathrm{~mm}^{2}$. The semiconductor cutting was followed by an intensive mechanical effect on the crystal, and, as the result, the obtained surface contained irregularities and damaged layer of different thickness that depends on the material nature. These irregularities and damaged layer can be partially removed by mechanical polishing. According to preliminary assessments, the damaged layer of $\mathrm{ZnSe}$ surface was $50-60 \mu \mathrm{m}$ as a result of cutting by the developed method, while after cutting $\mathrm{ZnSe}$ with a diamond wheel, it is much larger and reaches $100 \ldots 150 \mu \mathrm{m})[1,2]$.

Mechanical polishing the samples. Polishing $\mathrm{ZnSe}(\mathrm{I}), \mathrm{ZnSe}(\mathrm{II}), \mathrm{ZnSe}(\mathrm{Al}), \mathrm{ZnSe}(\mathrm{Te})$ plates after cutting by our developed method should be performed using abrasive powder with grain sizes M 10, M 5 and M 1, or diamond powders ASM 28/20, ASM 10/7, ASM 5/3, ASM 3/2, ASM 2/1 and ASM 1/0. The polishing mixture is prepared in the form of abrasive powders aqueous suspensions with distilled water. The process should be carried out on a glass grinder, alternately treating the plate with both sides within 15 min by each abrasive (in order to decrease abrasive grit) depending on the thickness of the damaged layer that must be removed. After this, the samples should be thoroughly washed with warm distilled water using the addition of a small amount of detergent, then several times with distilled water and dried in air. The elimination rate of the surface layer was different depending on the nature of these materials and abrasive grit (Table 2). The $\mathrm{ZnSe}(\mathrm{Al})$ material elimination rate was $6 \mu \mathrm{m} / \mathrm{min}$ when we made polishing by abrasive diamond powders ASM 28/20, and by powder ASM 5/3 amounts to $4 \mu \mathrm{m} / \mathrm{min}$. For $\mathrm{ZnSe}(\mathrm{Te})$ crystals the surface layer elimination rate with abrasives ASM 28/20 is equal to $18 \mu \mathrm{m} / \mathrm{min}$ and $2 \mu \mathrm{m} / \mathrm{min}$ with diamond powder ASM 5/3.

This small surface layer elimination rate of $\mathrm{ZnSe}(\mathrm{Al})$ samples may be related to the fact that these crystals were thermally annealed in atmosphere of zinc, and $\mathrm{ZnSe}(\mathrm{Te}$ ) crystals were prepared without thermal annealing. After mechanical polishing of undoped and doped $\mathrm{ZnSe}$, the damaged layer thickness was about 10 to $30 \mu \mathrm{m}$ [1], and the layer can be removed using CMP. 
Table 2. The elimination rates of ZnSe crystals surface layer during mechanical polishing by free abrasives.

\begin{tabular}{|c|c|c|}
\hline \multirow{2}{*}{ Semiconductor } & \multicolumn{2}{|c|}{$\begin{array}{c}\text { The elimination rate of the } \\
\text { surface layer, } \mu \mathrm{m} / \mathrm{min}\end{array}$} \\
\cline { 2 - 3 } & $\mathbf{M 1 0}$ & $\mathbf{M 5}$ \\
\hline $\mathrm{ZnSe}(\mathrm{I})$ & 154.5 & 47 \\
\hline $\mathrm{ZnSe}(\mathrm{II})$ & 145.5 & 30 \\
\hline $\mathrm{ZnSe}(\mathrm{Al})$ & 109 & 67 \\
\hline $\mathrm{ZnSe}(\mathrm{Te})$ & 89.5 & 71 \\
\hline
\end{tabular}

Chemical-mechanical polising. Elimination of the surface damaged layer should be carried out using the CMP method. To make the CMP process for $\mathrm{ZnSe}(\mathrm{I})$, $\mathrm{ZnSe}(\mathrm{II}), \mathrm{ZnSe}(\mathrm{Al}), \mathrm{ZnSe}(\mathrm{Te})$ samples, we developed polishing solution at a volume ratio of components: $10 \mathrm{H}_{2} \mathrm{O}_{2}: 10 \mathrm{HBr}: 80 \mathrm{EG}$ characterized by small etching and high polishing ability. We recommend holding the etching mixture for 2 hours in order to achieve the maximum concentration of free bromine, which is formed during interaction of etching components. The CMP process of wafers that are prepared in etching solution with the rate $2 \mathrm{ml} / \mathrm{min}$ was carried out for $5 \mathrm{~min}$ at $T=298 \mathrm{~K}$ using a cambric tissue covered glass polisher, and CMP rate do not exceed $20 \mu \mathrm{m} / \mathrm{min}$ (Table 3).

After CMP process, the samples were immediately washed in $0.01 \mathrm{M}$ aqueous solution of $\mathrm{Na}_{2} \mathrm{~S}_{2} \mathrm{O}_{3}$, distilled water and isopropyl alcohol (IPA) using ultrasound (US) at $T=308 \mathrm{~K}$ as follows:

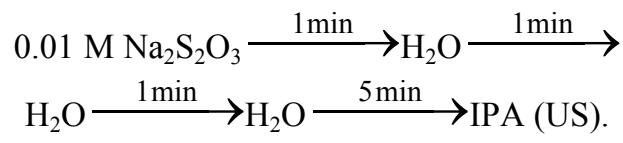

Then the samples were dried in air flow. As a result of our treatment techniques, the shiny polished surface of $\mathrm{ZnSe}(\mathrm{I}), \mathrm{ZnSe}(\mathrm{II}), \mathrm{ZnSe}(\mathrm{Al})$ and $\mathrm{ZnSe}(\mathrm{Te})$ crystals was obtained, which was not oxidized against time and not covered by cloudy films. It was found that the storage of ZnSe samples after CMP is better in solution (isopropanol or dimethylformamide) than in air, as the polished surfaces did not lose their properties for several months.

Table 3. The CMP rates of undoped and doped $\mathrm{ZnSe}$ crystal surfaces.

\begin{tabular}{|c|c|}
\hline Semiconductor & The CMP rates, $\mu \mathrm{m} / \mathrm{min}$ \\
\hline $\mathrm{ZnSe}(\mathrm{I})$ & 17.1 \\
\hline $\mathrm{ZnSe}(\mathrm{II})$ & 14.5 \\
\hline $\mathrm{ZnSe}(\mathrm{Al})$ & 13.8 \\
\hline $\mathrm{ZnSe}(\mathrm{Te})$ & 18.2 \\
\hline
\end{tabular}

Inter-cleaning the ZnSe surface after each stage of treatment. After each stage of mechanical treatment carried out surface inter-cleaning of undoped and doped $\mathrm{ZnSe}$ single crystals should be made for removing dirt from the surface of plates produced during cutting, grinding and mechanical polishing. At first, to remove the physical or mechanical contamination (dust, abrasive particles, metallic materials and semiconductor crumbs, which are formed during grinding) by rinsing in distilled water with addition of surface-active substances. Removing organic contaminants (grease, glue, residues, suspension, and fingerprint) was conducted by degreasing in organic solvents (ethanol, acetone), after which the crystals should be thoroughly dried in flow of purified air before the following technological operations.

The crystal dissolution rates were registered by reducing its thickness before and after etching with an electronic indicator TESA DIGICO 400 with an accuracy $\pm 0.2 \mu \mathrm{m}$.

The investigation of $\mathrm{ZnSe}$ surface state after different stages of mechanical and chemical treatments were carried out using the universal stage microscope ZEISS JENATECH INSPECTION with a digital camcorder with magnification from $25 \times$ to $1600 \times$.

Crystal surface morphology was studied at room temperature by atomic force microscope (AFM) Nano Scope IIIa Digital Instrument company using the periodic contact mode. The silicon probes $\mathrm{NCH}-50$ with a nominal tip radius of curvature $\approx 10 \mathrm{~nm}$, with the resonance frequency of $320 \mathrm{kHz}$, and console stiffness $42 \mathrm{~N} / \mathrm{m}$ were used for measurements.

\section{Results and discussion}

When we were studying chemical polishing peculiarities of undoped and doped $\mathrm{ZnSe}$ crystals in $\mathrm{H}_{2} \mathrm{O}_{2}-\mathrm{HBr}$ solutions, it was found that the most perspective for the creation of polishing etchants with average speeds of material removal $(12-22 \mu \mathrm{m} / \mathrm{min})$ are solutions containing 10-16 vol. $\% \mathrm{H}_{2} \mathrm{O}_{2}$ in $\mathrm{HBr}$. An introduction of the solvent in such etchant reduces the concentration of an active component in the solution. As a result, we can obtain lower polishing rates and significantly better polishing properties.

For CMP of undoped and aluminum or tellurium doped zinc selenide samples we have developed the polishing solution (in vol.\%): $10 \mathrm{H}_{2} \mathrm{O}_{2}: 10 \mathrm{HBr}$ :80 EG at $v \approx 13 \mu \mathrm{m} / \mathrm{min}$. This etchant is characterized by high polishing ability and small etching rates (Table 3 ).

The results of electron microscopy for $\mathrm{ZnSe}$ surface after treatment by CMP methods in solution $\mathrm{H}_{2} \mathrm{O}_{2}-\mathrm{HBr}-\mathrm{EG}$ suggest high quality of treated surface (Fig. 1).

The atomic force microscopy was used to evaluate the effectiveness of our developed etching compositions. The results of electron and atomic force microscopy (Fig. 2) of ZnSe surface after treatment by CMP and $\mathrm{CDP}$ in $10 \mathrm{H}_{2} \mathrm{O}_{2}: 10 \mathrm{HBr}: 80 \mathrm{EG}$ solution (in vol.\%)

(C) 2013, V. Lashkaryov Institute of Semiconductor Physics, National Academy of Sciences of Ukraine 


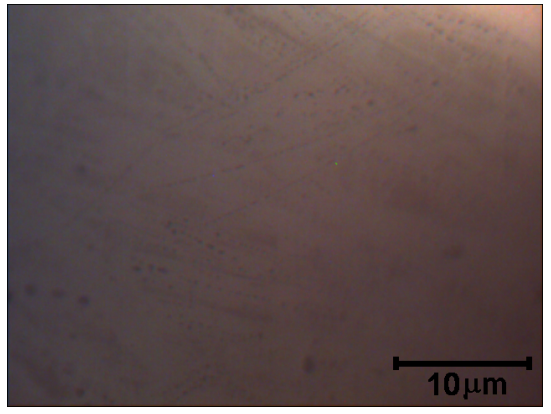

$a$

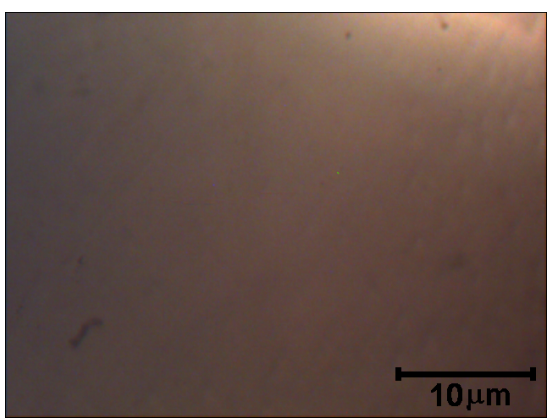

$c$

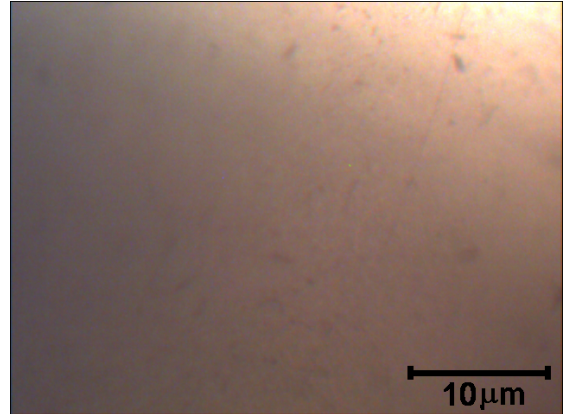

$b$

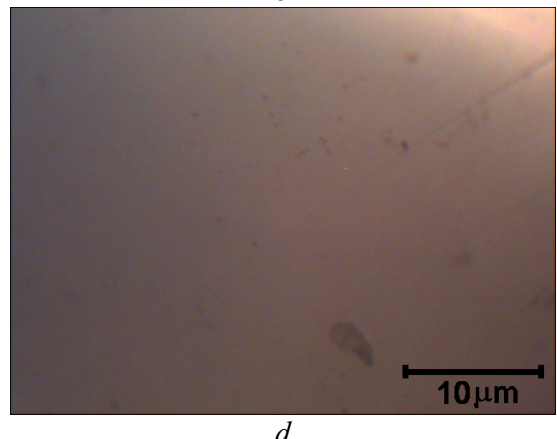

$d$

Fig. 1. Surface morphology of crystals: (a) - ZnSe(I), (b) - ZnSe(II), (c) - ZnSe(Al), (d) - ZnSe(Te) after CMP by the solution (in vol.\%) $10 \mathrm{H}_{2} \mathrm{O}_{2}: 10 \mathrm{HBr}: 80 \mathrm{EG}$.

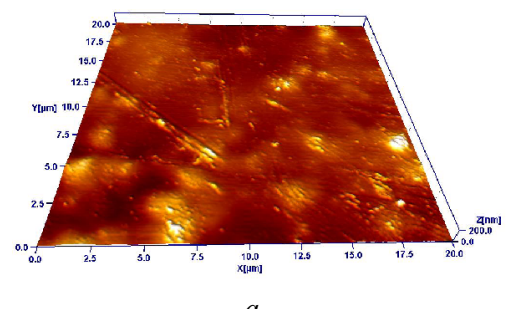

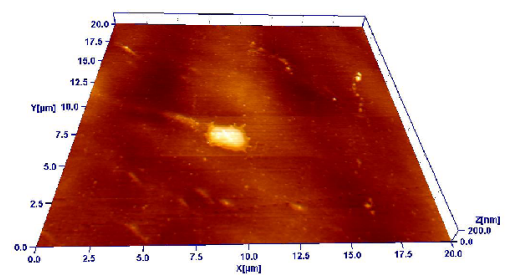

$b$

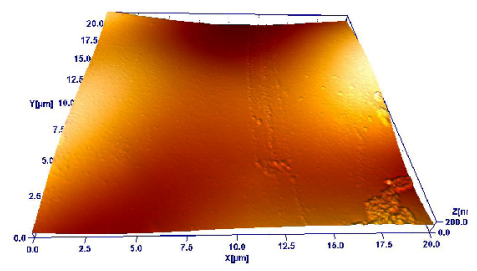

$c$

Fig. 2. Atomic force microscopy of the surface after the CMP process in the solution (in vol.\%) $10 \mathrm{H}_{2} \mathrm{O}_{2}: 10 \mathrm{HBr}: 80 \mathrm{EG}$ to (a) $\mathrm{ZnSe},(\mathrm{b})-\mathrm{ZnSe}(\mathrm{Al}),(\mathrm{c})-\mathrm{ZnSe}(\mathrm{Te})$.

confirms the high quality of treated surface, because its roughness parameters corresponding to polished surface semiconductor materials 2-14 nm (Table 4).

According to profilographic researches of $\mathrm{ZnSe}$ crystals, the surface roughness after chemical treatment with $\mathrm{H}_{2} \mathrm{O}_{2}-\mathrm{HBr}-\mathrm{EG}$ solutions from data of different methods corresponds: after CMP rms $=1.95-6.03 \mathrm{~nm}$, and after CDP rms $=9.6-13.5 \mathrm{~nm}$.

The results of $\mathrm{ZnSe}$ samples AFM after CDP by solution composition (in vol.\%) $16 \mathrm{H}_{2} \mathrm{O}_{2}: \quad 84 \mathrm{HBr}$ (Fig. 3) suggest that there is a surface deterioration in contrast to results obtained after the CMP process. This may be due to the presence of different dopants in researched crystals ( $\mathrm{Al}$ or $\mathrm{Te}$ ) and their influence on the process of dissolution of the material.

The appearance of "terraces" can be traced, which may result from the transition between the blocks or from wurtzite to sphalerite modification during crystal growth. The presence of shallow grooves (Fig. 3c) may indicate the etching of tellurium inclusions. The surface roughness value for crystals after the CDP process is slightly higher in comparison with its value after CMP (Table 4), which may be due to insignificant deterioration of the surface, and to formation of oxide film $\mathrm{ZnO}$, and this oxide film is removed by CMP, probably because of the mechanical component of the process.

Table 4. Surface roughness of undoped and doped $\mathrm{ZnSe}$ after chemical treatment in the new bromine emerging etchants.

\begin{tabular}{|c|c|c|}
\hline \multirow{2}{*}{ Semiconductor } & \multicolumn{2}{|c|}{ rms value, $\mathrm{nm}$} \\
\cline { 2 - 3 } & CMP & CDP \\
\hline $\mathrm{ZnSe}$ & 6.0 & 13.5 \\
\hline $\mathrm{ZnSe}(\mathrm{Al})$ & 2.0 & 11.1 \\
\hline $\mathrm{ZnSe}(\mathrm{Te})$ & 2.1 & 9.6 \\
\hline
\end{tabular}

\section{(C) 2013, V. Lashkaryov Institute of Semiconductor Physics, National Academy of Sciences of Ukraine}




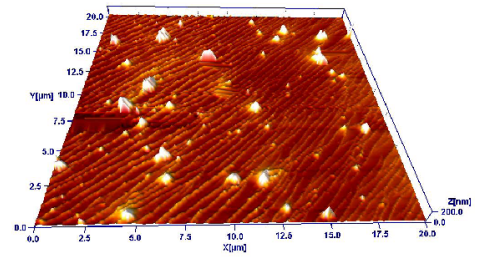

$a$

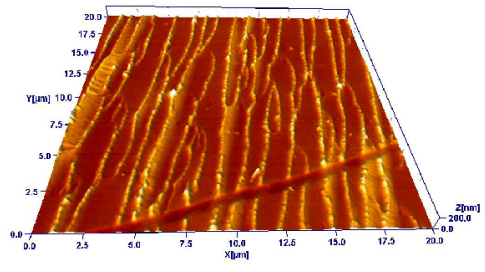

b

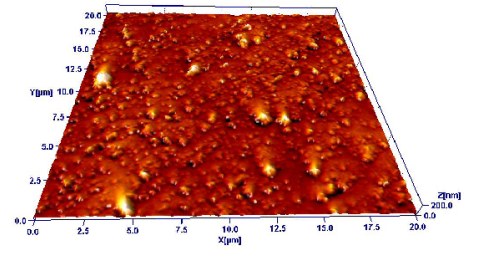

c

Fig. 3. Atomic force microscopy of the surface after the CDP process in the solution (in vol.\%) $16 \mathrm{H}_{2} \mathrm{O}_{2}: 84 \mathrm{HBr}$ to (a) - $\mathrm{ZnSe}$, (b) $-\mathrm{ZnSe}(\mathrm{Al})$, (c) $-\mathrm{ZnSe}(\mathrm{Te})$.

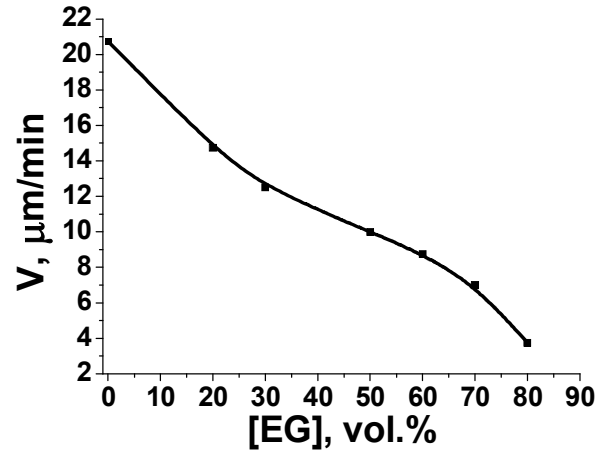

a

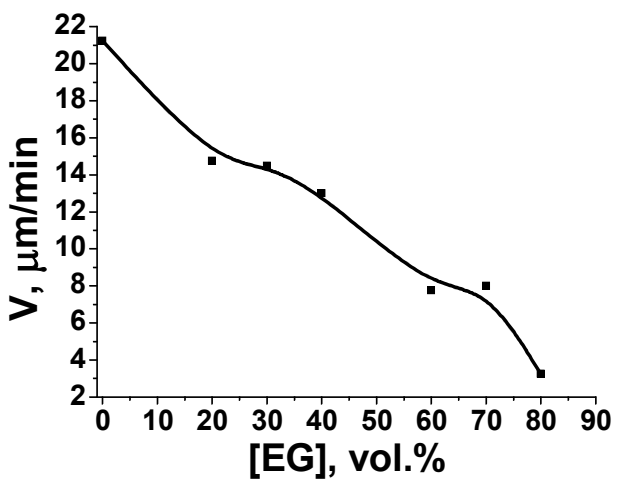

$c$
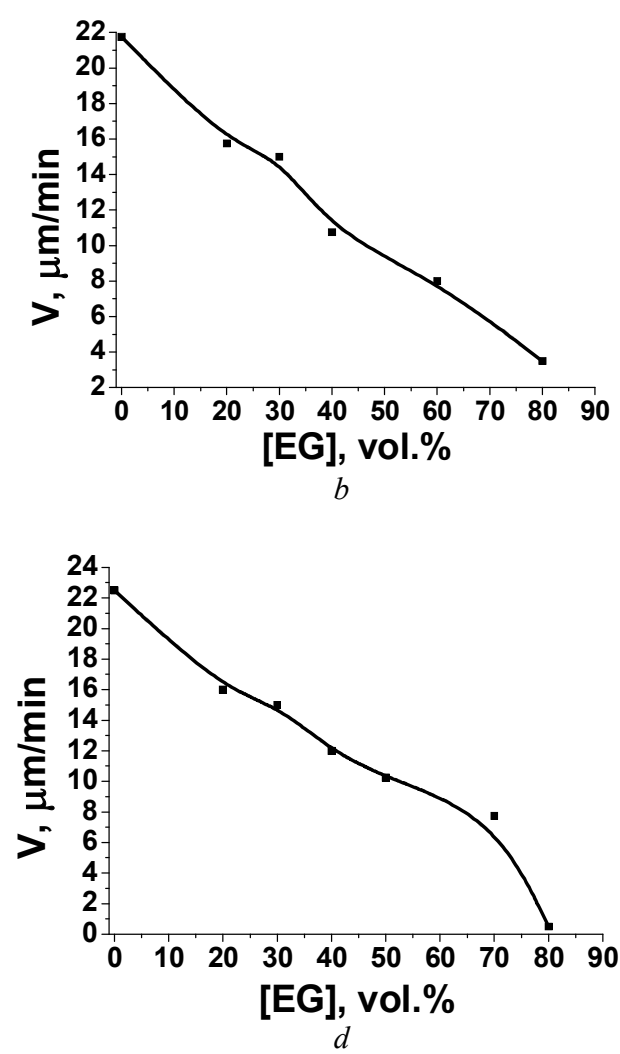

Fig. 4. Dependence of the chemical-mechanical polishing rate of $\mathrm{ZnSe}(\mathrm{I})$ (a), $\mathrm{ZnSe}(\mathrm{II})$ (b), $\mathrm{ZnSe}(\mathrm{Al})$ (c) and $\mathrm{ZnSe}(\mathrm{Te})$ (d) on the EG content in the base etchant (BS composition, in vol. $\%-10 \mathrm{H}_{2} \mathrm{O}_{2}: 10 \mathrm{HBr}: 80 \mathrm{EG}$ ).

When we select an etchant to create on its basis the polishing compositions for CMP, we should be aware that due to mechanical component the elimination rate of semiconductor material surface by this method can be several times higher in comparison with the same etchant for CDP. According to the experiment results, the etchant composition (in vol.\%) $10 \mathrm{H}_{2} \mathrm{O}_{2}: 10 \mathrm{HBr}: 80 \mathrm{EG}$ were selected as the basic solution (BS) that shows good polishing properties during CDP.

A certain amount of viscosity modifier - EG was additionally introduced to the BS in order to develop the slow polishing etchants for CMP of investigated materials, to reduce the rate of CMP (decrease in the active component content) and to improve the surface quality directly before the CMP process. It was found (Fig. 4) that the CMP rate was gradually decreased with increasing the additionally introduced amount of EG to the basic etchant.

Thus, with increasing the EG content from 20 up to $80 \mathrm{vol} \%$ in BS, the mirror shiny surface of $\mathrm{ZnSe}$ samples was obtained. All etching compositions of this range have the high polishing properties for both undoped and doped $\mathrm{ZnSe}$ crystals, while the rate of CMP was decreased from 22.5 to $0.5 \mu \mathrm{m} / \mathrm{min}$.

According to the Table 5, we can evaluate expediency of using etching compositions (in vol.\%) $(50-80) \mathrm{BS}:(20-50) \mathrm{EG}$ for thinning the semiconductor wafers to the specified size.

\section{(C) 2013, V. Lashkaryov Institute of Semiconductor Physics, National Academy of Sciences of Ukraine}


Table 5. Optimized etchants compositions $\mathrm{H}_{2} \mathrm{O}_{2}-\mathrm{HBr}-$ solvent for CMP of $\mathrm{ZnSe}$ crystals.

\begin{tabular}{|c|c|c|c|c|}
\hline \multirow{2}{*}{$\begin{array}{c}\text { Volumetric } \\
\text { ratio, (vol.\%) } \\
{[\text { BS] : [EG] }}\end{array}$} & \multicolumn{4}{|c|}{ Etching rate, $\mu \mathrm{m} / \mathrm{min}$} \\
\cline { 2 - 5 } & ZnSe (I) & ZnSe (II) & ZnSe (AI) & ZnSe (Te) \\
\hline 100 BS : 0 EG & 20.8 & 21.8 & 21.3 & 22.5 \\
\hline 80 BS : 20 EG & 14.8 & 15.8 & 14.8 & 16 \\
\hline 70 BS : 30 EG & 12.5 & 15 & 14.5 & 15 \\
\hline 60 BS : 40 EG & 13 & 10.8 & 13 & 12 \\
\hline 50 BS : 50 EG & 10 & 17 & 15.3 & 10.3 \\
\hline 40 BS : 60 EG & 8.8 & 8 & 7.8 & 2.3 \\
\hline 30 BS : 70 EG & 7 & 10.8 & 8 & 7.8 \\
\hline 20 BS : 80 EG & 3.8 & 3.5 & 3.3 & 0.5 \\
\hline
\end{tabular}

\section{Conclusions}

We have found that $\mathrm{H}_{2} \mathrm{O}_{2}-\mathrm{HBr}-\mathrm{EG}$ etchants are stable in time and keep their polishing properties during 24 hours after preparation. A controlled polishing rate of these materials within $12 \ldots .22 \mu \mathrm{m} / \mathrm{min}$ allows development of polishing etchants for thinning the wafers to the specified sizes. The methods of electron and atomic force microscopy confirmed the high quality of the semiconductors surface after the chemical polishing process. The series of slow bromine emerging etching compositions (in vol.\%): $(20-40) \mathrm{BS}$ : $(60-80) \mathrm{EG}$ were developed as based on the experimental researches. They can be used for controlled thinning the plates to the specified size and finish polishing of single crystals and thin films. Thus, for CMP of undoped and aluminum or tellurium doped zinc selenide samples, we have developed polishing solution composition (in vol.\%) $10 \mathrm{H}_{2} \mathrm{O}_{2}: 10 \mathrm{HBr}: 80 \mathrm{EG}$ at $v=13.8-18.2 \mu \mathrm{m} / \mathrm{min}$. This etchant is characterized by a high polishing ability and small etching rates.

\section{References}

1. B.D. Lyft, V.A. Perevosshikov, L.N. Vozmilova, I.A. Sverdlin, K.G. Marin, Physical-chemical Methods of Semiconductors Surface Treatment. Radio i sviaz', Moscow, p. 136, 1982 (in Russian).

2. V.A. Perevoschikov, Chemical and dynamical processes of semiconductor surface polishing // Vysokochistye veschestva, 2, p. 5-29 (1995), in Russian.
3. V.N. Tomashuk, Z.F. Tomashyk, Chemical etching of II-VI semiconductor compounds // Neorgan. materialy, 29(5), p. 717-718 (1993), in Russian.

4. V.N. Tomashuk, Z.F. Tomashyk, Mechanical and chemical-mechanical treatment of II-VI semiconductor compounds // Neorgan. materialy, 30(12), p. 1498-1503 (1994), in Russian.

5. V.N. Tomashuk, Z.F. Tomashyk, A.V. Lyubchenko, A.V. Fomin, Liquid phase etching of II-VI semiconductor compounds and physical-chemical processes at the interface (Overview) // Optoelektronika i poluprovodnikovaya tekhnika, 28, p. 3-15 (1994), in Russian.

6. V.N. Tomashyk, Selective etching of zinc, cadmium and mercury chalcogenides // Neorgan. materialy, 31(3), p. 313-317 (1995), in Russian.

7. V.N. Tomashuk, Z.F. Tomashyk, Polishing etching of II-VI semiconductor compounds // Neorgan. materialy, 33(12), p. 1451-1455 (1997), in Russian.

8. Z.F. Tomashyk, V.N. Tomashuk, Physicalchemical interaction of II-VI and III-V semiconductors with etching liquid compositions // Condensirovannye sredy $i$ mezhfaznye granicy, 4(4), p. 336-341 (2002), in Russian.

9. R. Tenne, H. Flaisher, R. Triboulet, Photoelectrochemical etching of zinc selenide and nonuniform charge flow in Schottky barriers // Phys. Rev. B: Condens. Matter, 10, p. 5799-5804 (1984).

10. W.C. Hughes, C. Boney, M.A.L. Johnson et al., Surface preparation of $\mathrm{ZnSe}$ substrates for $\mathrm{MBE}$ growth of V-VI light emitters // J. Cryst. Growth, 175/176, p. 546-551 (1997).

11. R. Tenne, R. Haak, R. Triboulet, Electrochemical photocapacitance of zinc selenide: effect of photoelectrochemical etching // Berichte Bunsengesellschaft Phys. Chem., 91(6), p. 597-599 (1987).

12. R. Tenne, Y. Mirovsky, Y. Greenstein, D. Cahen D, Ternary chalcogenide-based photoelectrochemical cells. II. The $\mathrm{n}-\mathrm{CdZn} \mathrm{Z}_{2} \mathrm{Se}_{4} /$ aqueous polysulfide system // J. Electrochem. Soc., 129(7), p. 1506-1512 (1982).

13. A. Sagar, W. Lehmann, I.W. Faust, Etchants for ZnSe // J. Appl. Phys. 11, p. 5336-5338 (1968).

14. J. Gautron, C. Raisin, P. Lemagson, Optical and electro-optical behaviour of polished and etched zinc selenide single crystals // J. Phys. D: Appl. Phys., 15, p. 153-161 (1982).

15. N. Sankar, K. Ramachandrana, C. Sanjeeviraja, Growth and characterization of $\mathrm{ZnSe}$ and phosphorus-doped ZnSe single crystals // J. Cryst. Growth, 235, p. 195-200 (2002). 